\title{
Fracking in the UK Press: Threat Dynamics in an Unfolding Debate
}

\author{
Rusi Jaspal \\ De Montfort University, Leicester, UK \\ Brigitte Nerlich \\ University of Nottingham, Nottingham, UK
}

\begin{abstract}
Shale gas is a novel source of fossil fuel which is extracted by induced hydraulic fracturing, or "fracking." This article examines the the socio-political dimension of fracking as manifested in the UK press at three key temporal points in the debate on the practice. Three newspaper corpora were analysed qualitatively using Thematic Analysis and Social Representations Theory. Three overarching themes are discussed: "April-May 2011: From Optimism to Scepticism"; "November 2011: (De-)Constructing and Re-Constructing Risk and Danger; "April 2012: Consolidating Social Representations of Fracking." In this article, we examine the emergence and inter-relations between competing social representations, discuss the dynamics of threat positioning and show how threat can be re-construed in order to serve particular socio-political ends in the debate on fracking.
\end{abstract}

fracking; media; climate change; environmental communication; social representations theory; collective symbolic coping

\section{Citing this paper}

Jaspal, R. \& Nerlich, B. (in press). Fracking in the UK Press: Threat Dynamics in an Unfolding Debate. Public Understanding of Science.

\section{Acknowledgements}

The authors would like to thank Prof. Martin Bauer, Dr. Susan Howard and various anonymous reviewers for their valuable feedback on the paper. This work was supported by the ESRC (grant number RES-360-25-0068).

\section{Contact}

Dr Rusi Jaspal, Division of Psychology, School of Applied Social Sciences, Faculty of Health and Life Sciences, De Montfort University, Leicester LE1-9BH, United Kingdom. E-mail: rusi.jaspal@gmail.com 


\section{Fracking in the UK Press: Threat Dynamics in an Unfolding Debate}

Despite the negative environmental impacts of continued dependence upon fossils fuels, fossil fuels will nonetheless continue to provide the majority of the world's energy.' Novel fossil fuels are therefore being sought in a context where climate change mitigation technologies for $\mathrm{CO}_{2}$ reduction, such as carbon capture and storage and geoengineering, are being discussed in the media (Nerlich \& Jaspal, 2012, 2013). One of these novel sources of fossil fuel is shale gas that is extracted by induced hydraulic fracturing, or "fracking." Being a natural gas, fracking is often said to have a lower carbon footprint compared to other fossil fuels and to be a clean(er)/ "transitional" energy source (Engelder, 2011).

Fracking is the process whereby high-pressure water with additives is used to increase fissures in the rock layer and thereby extract shale gas embedded within the layer (Rahm, 2011). Despite being one of the most controversial fuel extraction technologies and climate change mitigation technologies to have emerged, fracking has not yet been studied in detail by social scientists (Jaspal, Turner \& Nerlich, in press). This article examines the sociopolitical debate on fracking as manifested in the UK press. In a thematic analysis study, we identify emerging social representations of the practice of fracking at three important junctures.

\section{Fracking: The Scientific Domain}

Fracking is a complex technology. There is no scientific consensus concerning the viability of fracking as a climate change mitigation technology and alternative source of energy. Howarth and Ingraffea (2011, p. 272) argue that, although shale gas has been represented as a "clean," "win-win" fuel, it is in fact uncertain, unclean and unsafe. They point to a number of risks, namely that (1) fracking can release dangerous levels of methane leading to high risk of explosions; (2) fracking-return fluids (e.g. bromides) can contaminate water; (3) the development of shale gas can seriously contaminate air quality, potentially increasing the risk of cancer. They argue that these risks must be managed in order to render fracking "more sustainable and less polluting" (p. 273).

Conversely, Engelder (2011) points to the necessity of addressing global warming, "a serious issue that fracking-related gas production can help to alleviate" (p. 274). Although Engelder acknowledges potential environmental risks, he argues that these can be managed through the use of "existing, and rapidly improving technologies and regulations" (p.274) and that there will be benefits for employment, the economy, national security, and the environment.

\section{Global Deployment of Fracking}

Fracking has a relatively long history in the US. After a series of pilot projects in the early 1970s, in 1977 the US Department of Energy approved large-scale fracking in tight sandstone formations (Forbis \& Kear, 2011). Since the late 1990s a natural gas "drilling boom" has been underway, which has led to considerable controversy due to the perceived risks associated with fracking (Negro, 2012). In 2010, Josh Fox directed the documentary film Gasland, in which he explored the experiences of residents of Colorado, Wyoming, Utah, Texas and other states in which fracking had been deployed. Through interviews with residents allegedly affected by fracking, Gasland attributed various chronic health problems and the contamination of air and water to fracking. Although the State of Colorado's Department of Natural Resources contested the factual accuracy of Gasland, challenging, for instance, the assertion that fracking can cause tap water to become flammable, the film stirred controversy and attracted considerable media attention. The film may have had some influence on public understanding of fracking. Another film, Promised Land (Van Sant, 
2012) was released in the US for general screening on 28 December 2012 and will probably reignite the fracking debate in the US and in the UK.

Unlike in the US, fracking is not yet a widespread practice in the UK. The energy firm Cuadrilla Resources was granted a licence for shale gas exploration along the coast of Lancashire in 2007. The company claimed that there could be up to 5.6 trillion cubic metres of shale located in the Bowland shale under Lancashire, which could drastically reduce Britain's reliance on imported fuel as the North Sea gas reserves ran out (Stephenson, 2012). In March 2011 the first fracking operation was performed near Blackpool. However, public concerns about the technology were exacerbated when tremors measuring 2.3 on the Richter scale were felt in Blackpool, followed by further seismic activity measuring 1.5 on the Richter scale. Fracking was suspended in June 2011.

In November 2011, Cuadrilla Resources released a report which confirmed the high probability that fracking triggered "minor seismic events" (Cuadrilla Resources, 2011, p. 2), but added that this was unlikely to occur in future operations. In April 2012, an official UK government report was published. Despite acknowledging the role of fracking in causing seismic activity in Blackpool, the report called for deployment of fracking albeit "subject to an effective monitoring system that can provide automatic locations and magnitudes of any seismic events in near realtime" (Green, Styles \& Baptie, 2012, p. 3). In December 2012, that is, after we began our analysis of UK press coverage of fracking, the UK government lifted the moratorium on fracking.

\section{Social Representations and Symbolic Coping}

This study is concerned with emerging social representations of the science, politics and practice of fracking. Social Representations Theory investigates how science makes its transition into everyday social thinking and infiltrates public understanding (Moscovici, 1963, 1988). A social representation constitutes a structure of values, descriptors and practices regarding a given social object, as well as "the elaborating of a social object by the community for the purpose of behaving and communicating" (Moscovici, 1963, p. 251). Social representations are context-dependent and create what one might call a shared social reality in which discussion of complex issues such as fracking can take place.

In his analysis of how representations are formed, Moscovici (1988) outlines two processes that underlie the formation of social representations, namely anchoring and objectification. Anchoring refers to the process of making something unfamiliar understandable by linking it to something familiar (Bauer, 1995). For a community to develop an understanding of the practice of fracking and its possible impacts on society, it must first be named and attributed familiar characteristics. Objectification is the process whereby unfamiliar and abstract objects are transformed into concrete and "objective" common-sense realities. Physical characteristics are attributed to a non-physical entity, essentially "materializing" the immaterial.

In this article, we focus on newspaper reporting on fracking, given that, "[a]s a forum for the discourses of others and a speaker in their own right, the media have a key part in the production and transformation of meanings" (Carvalho, 2007, p. 224). Our approach is consistent with that employed by other researchers conducting media analyses through the heuristic lens of Social Representations Theory (e.g. Joffe \& Haarhoff, 2002). We provide a detailed analysis of social representations of fracking at three points in time, that is before the reports of earthquakes, after these reports and after government reports about earthquake and other risks. ${ }^{2}$ This analysis provides insight into representational changes in the UK media over time and indications of how public perceptions and policies may in turn be shaped by such representations (Farr, 1993). 
In the field of public understanding of science and technology, Wagner and colleagues (Wagner, 2007; Wagner et al., 2002) have outlined a theory of Collective Symbolic Coping, which refers to the attempt by a collectivity to maintain its worldview in face of emerging novel technologies. In this paper, we focus on the UK press reporting on fracking in face of global challenges posed by climate change, energy supply and resource depletion, most importantly of fossil fuels, which challenge established worldviews. Wagner and colleagues posit four stages of symbolic coping: (1) awareness - a phenomenon is represented as being relevant and topical; (2) divergence - multiple images emerge, engendering uncertainty; (3) convergence upon a few dominant images, which decreases uncertainty; and (4) normalisation, which integrates dominant images into common knowledge and constructs the novel technological phenomenon as an aspect of everyday life. The theory provides "concrete assumptions about the social processes underlying the elaboration of imaginary understanding" (Wagner et al., 2002, p. 341), and therefore complements the focus on representational content in Social Representations Theory. The Collective Symbolic Coping model is useful for understanding how the media creates, manages and discards social representations of the practice of fracking, which are disseminated to the readership.

\section{METHOD}

\section{The Corpus}

Using the keywords "fracking" and "shale gas" on the Nexis® news database, we searched four leading UK broadsheet newspapers and generated three corpora of newspaper articles and comment pieces published at three temporal points in the debate on fracking. We decided to focus on UK broadsheet newspapers only (in particular four key players: The Telegraph, The Times, The Guardian and The Independent), as there was only very cursory attention to the issue of fracking in UK tabloid newspapers. This suggested that the broadsheet press was making a more important contribution to the formation of social representations of the practice of fracking.

The three temporal points were:

- 1 April - 31 May 2011, which signalled the beginning of the (traditional) media debate on fracking in the UK;

- 1 November - 30 November 2011, which featured coverage of the Cuadrillacommissioned report that confirmed a causal link between fracking and the seismic activity in Lancashire;

- 1 April - 30 April 2012, which featured coverage of a UK government report that approved the implementation of fracking in the UK.

The April-May 2011 corpus contained 57 articles; the November 2011 corpus 104; and the April 2012 corpus 180. In total, 341 articles were analysed. Given the high number of newspaper articles published in these periods (see figure 1), these corpora are useful as indicators of how the practice of fracking was represented by the UK media for a national readership. 


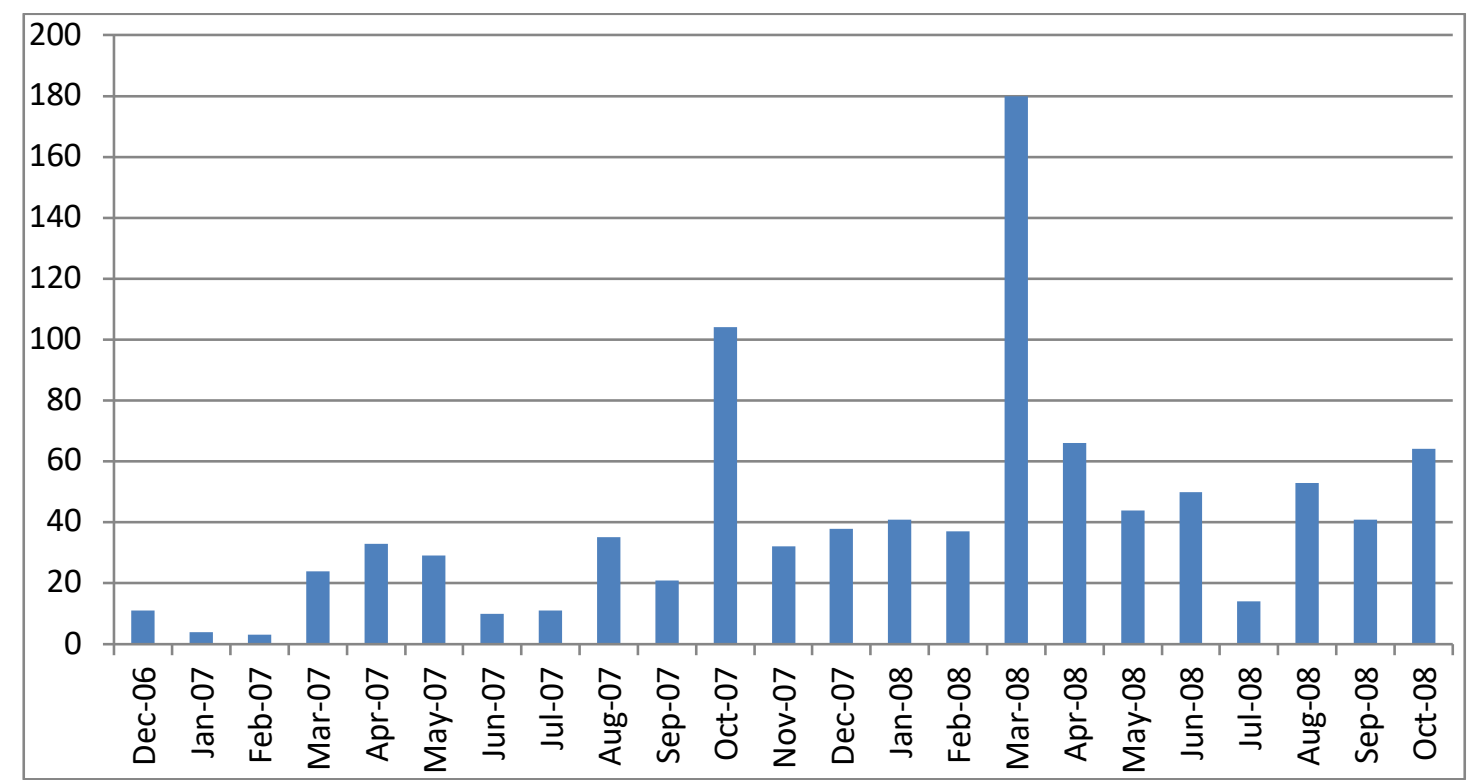

Figure 1: Number of articles on 'fracking'/'shale gas' in UK national newspapers between January 2011 and November 2012

\section{Analytical procedure}

The corpora were analysed using qualitative thematic analysis, which has been described as "a method for identifying, analysing and reporting patterns (themes) within data" (Braun \& Clarke, 2006, p. 78). These patterns of meaning are represented as "themes." Here thematic analysis is employed in order to clarify the structure of social representations of fracking as a political and media issue and the dominant rhetorical strategies used to construct them.

The authors read closely the three corpora of articles in order to acquire a high level of familiarity with the broader themes that were subsequently discussed analytically. The left margin of each article was used to note initial observations that captured essential qualities, units of meaning and apparent rhetorical techniques within the corpora. The authors discussed their respective initial codes, which included inter alia general tone, particular forms of language, comparisons, categorisations and emerging patterns in the data. The authors discussed potentially idiosyncratic interpretations of the data until consensus was reached.

These initial codes were collated into preliminary themes. These were arranged into a coherent structure, which best reflected the content of the corpora. This process resulted in the identification of eight superordinate themes, which are presented in the analysis section below. In addition to describing dominant themes in the corpora, we identified linguistic elements that performed the functions of anchoring and objectification. The superordinate themes can be considered social representations because they "assume a configuration where concepts and images can coexist without any attempt at uniformity, where uncertainty as well as misunderstandings are tolerated, so that discussion can go on and thoughts circulate" (Moscovici, 1988, p.233). Thus, positive social representations of fracking versus the threat representation described in this article, collectively, constitute a "framework" for understanding and discussing potentially "divergent concepts, inconsistent ideas and paradoxical meanings" (Rose et al., 1995, p.4).

In the analysis below, we provide extracts from the newspaper articles in order to exemplify the superordinate themes. 


\section{ANALYSIS}

This section outlines emerging social representations of the practice of fracking and pervasive rhetorical strategies used in the three periods. We found that most of the pro-fracking arguments were displayed in The Times and The Daily Telegraph and most anti-fracking arguments were found in The Guardian and The Independent.

\section{April/ May 2011: From Optimism to Pessimism Fracking as a provider of long-term security}

Reporting in The Telegraph and The Times in early April tends to construct fracking in positive terms, as a long-term solution to climate change. Accordingly, these outlets create awareness of the issue of fracking and begin to represent the practice in positive terms (Wagner et al., 2002). In one article, James Smith, the outgoing UK chairman of Shell, is quoted as stating that the combination of carbon capture and storage and fracking can constitute a "long term affordable source of green electricity." ${ }^{3}$ Smith speculates that "[t]here might be 200 years of shale gas supply available" which depicts fracking as uniquely positioned to mitigate climate change. In a context in which mitigation technologies are seldom represented as constituting more than short-term or partial solutions to climate change (Nerlich and Jaspal, 2012, 2013), fracking is constructed as providing a long-term solution. It is argued that current shale gas resources in the world could "boost global gas reserves by a staggering 40pc" and that "[i]n the UK, the technically recoverable shale gas resources could be more than double current North Sea reserves." "The positive social representation of fracking constructs it as providing long-term security, which is supported by the notions that (i) it is affordable; (ii) there is a large supply of it; (iii) it can boost existing reserves. Moreover, this relatively novel source of energy is anchored to "green electricity" which evokes imagery of "cleanliness" and long-term effectiveness, given the renewable nature of "green" energy. Media reporting in this period constructs fracking as a novel fossil fuel source as well as, rather paradoxically, a long-term "solution" to climate change, in the sense of ideally contributing to $\mathrm{CO}_{2}$ reductions.

Articles in these outlets depict the US as having "charged ahead" in fracking, while lamenting the possibility that in the UK "these novel sources of energy [will remain] locked away for many years to come." ' While in media reporting of carbon capture and storage, there is a focus on national pride in Britain's pioneering engagement with the technology (Nerlich \& Jaspal, 2013), here Britain's slow engagement with fracking is constructed as an impediment to the well-being of the nation. This is especially important as, unlike carbon capture and storage, whose economic and scientific viability has not yet been demonstrated in Europe, fracking seems to show more immediate and "enormous potential as a source of energy for the future."' Positive change is therefore positioned as within the nation's grasp, if only it had the courage to "unlock" it. Reluctance to deploy fracking on a larger scale is constructed as having potentially negative outcomes for economic recovery. In one article, public concern about fracking is represented as a "woe of the world" which could "cast a shadow over recovery."' In short, by reproducing the notion that fracking provides long-term security (acknowledged by the US), these outlets implicitly encourage engagement with fracking.

Fracking is metaphorically constructed as providing the world with "a breathing space." This objectification of the benefits of fracking performs a personifying function - the world is personified as an animate entity which is implicitly constructed as suffering the negative consequences of climate change and which therefore requires "breathing space."' Indeed, previous metaphor analytical research into the media and public debate concerning geoengineering has similarly found a personification of the earth in terms of a "patient" requiring a "medical fix" (Nerlich \& Jaspal, 2012). Similarly, in an article in The Telegraph 
fracking is metaphorically represented as a "global panacea for the world's energy shortage.", These personifying metaphors objectify fracking as an effective solution in the long-run, both as an energy source and as a "remedy" for climate change.

Following Collective Symbolic Coping, there is a convergence of positive images of fracking, which includes the notion that fracking brings about long-term security.

\section{Representing the practice of fracking as a threat}

Later in the corpus, The Guardian and The Independent begin to engage with fracking, and construct a counter-representation that fracking poses various environmental, political and economic threats (henceforth, the threat representation). There is a convergence upon negative images of fracking as a threat (Wagner et al., 2002). Initially, fracking is represented as a threat to "green energy." The metaphor of the "carbon footprint" is increasingly employed in order to construct fracking as a "dirty" technology..$^{10}$ There is a tendency to represent fracking as being "dirtier" than these other sources. Crucially, this argument is presented in order to argue that fracking constitutes a counterproductive climate change mitigation technology, which is more damaging for the environment than usual $\mathrm{CO}_{2}$ contributors. This serves to contest the notion that fracking provides energy security in the long-term (and that it is a climate change mitigation technology).

Green energy is represented as constituting a more sustainable energy alternative. One article employs the metaphor of fracking "choking" green energy, which depicts fracking as harmful not only to the environment, but also to the "green" technologies that could reduce $\mathrm{CO}_{2}$ emissions." The metaphor of "choking" objectifies fracking in terms of a life-threatening phenomenon which deprives green energy of the fundamental elements for survival. This constitutes a metaphorical counterpoint to the "breathing space" metaphor employed by profracking outlets.

In the middle of April, media reporting of fracking in anti-fracking outlets began to focus largely upon the US documentary film Gasland (Fox, 2010). Drawing upon material from the documentary film, articles construct the "side effects" of fracking as "potentially lethal," ${ }^{12}$ which accentuates the threat representation - it is threatening not only to the environment but also to the human beings that inhabit it. Supporting notions of the threat representation include (1) "disastrous gas leaks", (2) "land contaminated by the chemicals used in extraction" and (3) "drinking water rendered unsafe." The notion of gas leaks draws heavily upon disaster imagery through the use of terms such as "disaster" and "catastrophe." Both land and drinking water, that is, the environment and human life, are subject to threat.

In later reporting, the threat representation constructs health concerns. One article argues that fracking employs "a battery of chemicals - including carcinogens such as benzene, ${ }^{13}$ which constructs fracking as a potential cancer risk. Another article refers to fracking as an "energy source that seems, in the US, to have released cancer-causing chemicals and radiation into the water supply." ${ }_{14}$ The anchoring of fracking to cancer renders the unfamiliar and uncertain technology in terms of familiar health risks - a risk of cancer, as well as asphyxiation and explosion. This constructs fracking as a threat (in this case, to human life)..$^{15}$

The threat representation incorporates the concerns of laypeople. Articles begin to focus on the fracking project in Blackpool and strategically quote members of the council and general public in order to highlight the "unease" and "fears" within the community.$^{16}$ The chairman of Blackpool's Green Party is quoted as referring to fracking as "catastrophic" and a "disaster in the making," both in terms of the potential health concerns (i.e. "cancer-causing chemicals") and global warming given that it allegedly "destabilises our planet's climate." These concerns are made to appear reasonable and legitimate in light of the Gasland film, 
since they are no longer solely the words of a documentary film but rather those of residents of an area in which fracking is to be deployed.

\section{Defending the practice of fracking through positive images}

At the end of this period, reporting in The Telegraph and The Times exhibits a defensive response to growing scepticism regarding fracking and the emerging threat representation. In response to the divergent images of fracking, both as a provider of long-term security and as a threat, these more sympathetic outlets attempt to converge upon positive images in order to defend the practice of fracking (Wagner et al., 2002). In a letter to the editor of The Independent ${ }^{18}$ fracking is constructed as a long-standing technique ("quite an old one"), which positions the technology within the bounds of "normality," dispelling the unfamiliarity and uncertainties that are increasingly outlined in media reporting. This is reinforced in a later letter published in The Independent, ${ }^{19}$ which states that fracking is "as old as the hills." Here, there is an attempt to decrease "fantasy-filled and menacing images" of fracking (Wagner et al., 2002, p. 327), and therefore in the press the convergence and normalisation processes seem to function in tandem.

The threat to human health posed by fracking is also downplayed. In one letter, ${ }^{20}$ it is acknowledged that the chemicals used in fracking have been problematic in the US context but that "[t]he regulation of extractive industries is much better in the UK than the US." This serves to disassociate the alleged hazards and risks reported in Gasland from the UK context. On the other hand, The Telegraph and The Times also invoke fracking in the US in order to exemplify the, mainly economic, benefits of fracking.

An important means of constructing the long-term security of fracking is to contest the emerging counter-representation concerning the effectiveness of competing alternative energy sources and mitigation technologies, which is observable in The Guardian and The Independent. There is an attempt to decrease the divergence of images. One article in the corpus entitled "Blowing billions on the fantasy of wind power" ${ }^{21}$ constructs wind power as a misguided illusionary technology that will not to be effective in its goal to provide sustainable energy. Articles in the corpus refer to the "green mantra," which is said to drive investment in wind power. Use of the metaphor "mantra" suggests some form of religious doctrine, which requires acceptance and endorsement, rather than any rational, critical thinking on the basis of scientific investigation. This serves to herald a more beneficial and rational alternative, namely fracking.

\section{November 2011: (De-)Constructing and Re-constructing Risk and Danger Fracking as a danger: Building on the threat representation}

During this period, the core focus of media reporting on fracking is on the seismic activity in Lancashire. The Guardian and The Independent consistently refer to fracking as an inherently dangerous technology, for which there is now seemingly concrete and local evidence. These outlets tend to employ the term "earthquake,"which evokes imagery of destruction and disaster, rather than less grave-sounding terms such as "seismic activity" or "tremors," which are used in The Times and The Telegraph. The earthquake term reinforces the threat representation. The Guardian and The Independent also actively anchor the process of fracking to earthquakes through the use of violent and aggressive metaphors. For instance, articles in these outlets tend to use the metaphors of "forcing" and "blasting" chemicals into the rock in order to describe the process and proceed to attribute earthquakes to fracking. ${ }^{22}$

There is also an accentuation of the scale and gravity of the seismic activity. In one article, the earth tremors in Blackpool are represented as a "huge number of seismic movements." ${ }_{23}$ This contrasts with media representations in The Times and The Telegraph which attenuate their scale and gravity. Moreover, in several articles, Labour MPs are 
strategically quoted as viewing the Lancashire earthquakes as "alarming" and as stating that "people had got a right to be frightened," thereby constructing fear as an appropriate and proportionate response to fracking. ${ }^{24}$ This rationalisation of fear by a local MP, a representative of the residents of this area, constructs fracking as posing a danger. This is in stark contrast to media reporting in The Times and The Telegraph, which represents the seismic activity in Blackpool as an isolated and exceptional set of events.

The Guardian and The Independent repeat the observation that fracking has been banned in France, New York, Quebec and parts of Switzerland. This suggests that other nations have already recognized the inherent "dangers" of fracking and that the UK ought to follow suit. Indeed, several articles compare fracking in the UK to fracking overseas - in particular, the US. One article states that "Oklahoma earthquakes may be linked to fracking" and that there is "a more than twentyfold jump in the number of earthquakes in the past two years." ${ }_{25}$ The juxtaposition of reporting on the earthquakes in Oklahoma and the "smaller tremors" in Blackpool serves to construct semantic linkage between seismic activity in both geographical contexts, thereby generalising reports of the "grave" and "increasing" earthquakes in Oklahoma to the UK context.

Articles in The Guardian and The Independent highlight not only local threats but also threats to reduce global greenhouse gas emissions. They strategically quote representatives of the anti-fracking pressure group Frack Off in order to construct fracking as a threat to technologies, which are supposed to reduce emissions. Representatives metaphorically refer to fracking as "draining cash away from environmentally friendly energy development" and as "damaging government efforts to boost renewable energy production. ${ }^{26}$ It is argued that "[e]xtracting shale gas would suck vital funding away from clean and safe energy alternatives that could create thousands more jobs." Other articles in the corpus refer to fracking as an "extreme energy" which consists of "scraping the bottom of the barrel, sucking the last, most difficult-to-reach fossil fuels from the planet at a time when we should be looking for sustainable alternatives." ${ }^{7}$ The aggressive, moribund metaphors of draining away, damaging, scraping and sucking away and the categorisation of fracking as an "extreme energy," collectively, represent the practice of fracking as extracting and dissipating "vital" aspects of life, which could result in destruction and disaster, and as greedily and aggressively violating the earth and environment. There is convergence upon negative metaphorical images of harm and destruction (Wagner et al., 2002).

\section{Fracking and seismic activity}

Articles in The Telegraph and The Times begin to acknowledge the reported link between fracking and the seismic activity in Blackpool. However, the outlets attenuate these links by stressing the normality of minor tremors in that region, the fact that future fracking will have learned lessons from these events, but also, by referring to the tremors as "a public relations disaster" ${ }^{28}$ rather than as evidence of any inherent hazard or risk. Thus, the public reaction to the earthquakes, rather than the earthquakes themselves, is said to undermine fracking. The argument that "[p]ublic perception is a force to be reckoned with" serves to construct the public as entrenched in its collective belief in the "danger" of fracking. Within this context, the article employs the metaphor of "keep[ing] the shale gas flame alight" when it "could be choked off in its infancy." Although it is acknowledged that fracking caused seismic activity in this particular case, these metaphors construct fracking as the "victim" of unreasonable and unfounded scepticism. This contrasts with the counter-argument that fracking "chokes off" investment in alternative or green energy, which is framed as unreasonable. This too serves to limit divergence of images of fracking. 


\section{Representing green energy as the "real" threat}

Although these outlets acknowledge the link between fracking and seismic activity, they construct political, rather than scientific, factors as being pivotal in the debate on fracking. It is noted that, although fracking is not perfect, green energy will have adverse outcomes for the economy and society. There is an introduction of divergent images (Wagner et al., 2002), which in turn serves to re-direct the threat representation that has become prevalent in media reporting on fracking towards another target. Letters to the editor in The Times and The Daily Telegraph problematize the notion that "green energy" constitutes the solution to Britain's energy needs and attempt to re-establish the notion that fracking provides security in the long-run. In one such letter, ${ }^{29}$ "soaring energy costs" are attributed to "the [Energy] minister's obsession with renewable energy." Rising energy costs (which are attributed to renewable energy) are said to "cripple businesses and send many homes into fuel poverty, harming our economic recovery." While articles on fracking in The Guardian and The Independent and media reporting of climate change, more generally, tend to focus on threats to the planet and environment (Jaspal \& Nerlich, in press), here the constructed "threat" centres on people's livelihoods and on Britain's energy security, which is consistent with the political orientations of these news outlets.

\section{April 2012: Consolidating Social Representations of Fracking}

There is a consolidation (or "cultivation") of either positive or negative social representations of fracking, which the pro- and anti-fracking outlets seek to keep active (Bauer, 2002;

Wagner, 2007), despite the counter-representations that are introduced on the media agenda.

\section{Fracking, though imperfect, remains important}

Social representations that fracking pose a threat and a danger continue to permeate media reporting in The Guardian and The Independent. The admission in the Cuadrilla and the UK government reports that fracking was the likely cause of the seismic activity in Lancashire, on the one hand, and the popularity of the US documentary film Gasland, on the other, compelled advocates of fracking to take a stance on the threat and danger representations.

In one article,,$^{30}$ it is argued that "[w]ith our gas reserves we should be laughing," which implicitly laments the negative press that fracking has received and re-focuses our attention on the quantity of available shale gas. Another article in The Daily Telegraph entitled "IGas doubles estimates of its UK shale gas reserves," ${ }^{31}$ claims that "[ $\left.t\right]$ he increased estimate gave 'more confidence' to the notion that Britain could have more recoverable shale gas reserves than Poland." This comparison between the UK and Poland, a nation known for its successful fracking programme and shale gas reserves, provides a point of reference for understanding the quantity of available shale gas in the UK. Crucially, shale gas is anchored to North Sea oil reserves in order to illustrate the benefits of having copious shale gas reserves: "Even if the firm can extract only a fraction of it, it would still have an impact comparable to the exploitation of North Sea oil." Through the anchoring process, North Sea oil comes to represent a positive point of comparison for understanding the importance of fracking (Forsyth \& Kay, 1980).

It is observed that fracking is important despite potential risks. In another article in The Sunday Times, ${ }^{32}$ there is a UK-US comparison: "[S]hale gas could potentially offer us immense reserves of an easily exploitable and relatively clean energy source. It has been embraced in America, yet barely seems to feature in the Coalition's thinking." There is a glorification of shale gas which focuses primarily upon the quantity ("immense reserves") but also on the "cleanliness" of the energy source and the ease with which it can be exploited. The "benefits" for the US are contrasted with the UK's "disengagement" with fracking: "the 'shale gas' revolution that has turned America's deficit into a century of supply." ${ }_{33}$ 
Thus, the quantity of available shale gas, the low costs and security associated with it are again highlighted in order to construct a social representation that fracking remains important despite the criticisms. This reiterates the metaphor "shale gas revolution". One article $^{34}$ highlights this revolutionary potential by arguing that "[ $\left.t\right]$ he fact that it [shale gas] can heat our hovels, that something gets piped in to turn that tartare into burger, that we have plentiful hot water to keep the lice count down - all of these things are among the things that have made the last century or two the most pleasant to live in of all human history." Fracking is here portrayed as an instrument of human civilisation. This diverts attention from the potential risks and dangers and encourages readers to think about the role of shale gas in safeguarding the basic human needs of food, shelter and good health. There is convergence on positive images of fracking, which construct positive social representations.

\section{Denigrating the government report and rejecting positive images of fracking}

The danger and threat representations have dominated reporting in The Guardian and The Independent at all three temporal points. Media reporting in the third period crystallizes and consolidates the threat representation. Despite the potency of the threat representation, on 17 April 2012, the UK government published a report endorsing the implementation of fracking in the UK, subject to stringent safety measures.

The Guardian and The Independent systematically problematize the report in order to contest positive images of fracking and to sustain the threat and danger representations. This maintains convergence upon negative images of fracking. For instance, in one article, it is argued that the report "fails to put to bed all the concerns over seismic safety." ${ }_{35}$ The positive representations of the report concerning the quantity of shale gas available (observable in the April-May 2011 corpus) are contested by constructing the UK and US contexts as incomparable: "the crowded island we inhabit is very different to the wide open spaces of America, even if the gas fracker's heroic guesses on how much gas may be under our feet turn out to be correct." Estimations regarding the quantity of available shale gas are dismissed as mere "guesses."

The report is further denigrated through the rhetorical technique of strategic quoting, which provides "voice" to activists from the Frack Off pressure group. Elsie Walker, a Frack Off protestor, categorizes the report as "a seriously dangerous distraction" ${ }^{36}$ and argues that "[t]he DECC report is a transparent attempt to side step the vast array of issues, not just earthquakes, associated with shale gas extraction." Here the danger no longer derives from fracking but from government policy.

In another article, people are advised to be critical of the content of the report, and not to take it at face value: "Do not be distracted by the government's modest pause for consultation. ${ }^{37}$ Both the report and the government responsible for it are constructed as deliberately attempting to distract the public. The previous quote constructs the primary function of the report as malicious, that is, to "side step" important issues. The portrayal of the report as an active "attempt" to evade important issues constructs it as a conspiracy.

The "British people" are advised to be "extremely concerned that our legislators and advisers... have allowed themselves to be so blatantly manipulated by Cuadrilla," highlighting manipulation and an underlying conspiracy regarding fracking. Given that the UK government has officially endorsed fracking, provided that it adheres to stringent safety measures, these outlets appeal to readers directly and call for critical evaluation of the report: "Just how credulous do they [Cuadrilla] think that the British people are?" There is a call for public awareness of the "conspiracy" surrounding fracking: "People need to understand that the wave of unconventional gas development that is threatening the British Isles will bring with it far greater consequences than a number of small earthquakes." In short, the threat 
representation, which permeates reporting of fracking in The Guardian and The Independent, facilitates denigration of the report.

\section{DISCUSSION}

This article examines social representations of the practice of fracking disseminated in four broadsheet newspapers: The Times and The Daily Telegraph, which are more sympathetic towards fracking, and The Guardian and The Independent, which generally oppose it. The Times acquired a right-of-centre political leaning subsequent to its acquisition by Rupert Murdoch's News International in the 1980s and has traditionally been more sceptical regarding environmental issues, such as climate change. Similarly, The Daily Telegraph has now become famous for its largely climate-sceptic position, especially through the publication of blogs by James Delingpole after the climategate affair in 2009. These outlets are constructing positive social representations of the practice of fracking and disseminating them primarily to a readership that is exposed to a more sceptical stance on climate change (Jaspal, Nerlich \& Cinnirella, in press). Conversely, The Guardian and The Independent have left-of-centre and liberal, left-of-centre political orientations, respectively, and have largely been supportive of environmental issues. Given that fracking is widely represented as posing a threat to the environment and to "climate targets," these representations appear to be consistent with the ideological tendencies of the outlets. The more environmentally conscious readership of these outlets is the principal recipient and co-constructor of negative social representations of the practice of fracking.

This article goes beyond traditional thematic media analyses of environmental issues in examining the dynamics of the debate on fracking over time through the heuristic lens of Social Representations Theory and the Collective Symbolic Coping model. We argue that the notion of threat plays an important role in the debate, and may induce public uncertainty and fear about fracking and competing energy sources (see also Joffe, 2003). Secondly, in a diverse and contested representational field, there is a tendency to use social representations to defend or contest fracking through the use of positive and negative images of the technology, respectively, and through the use of strategic rhetorical techniques.

\section{The dynamics of threat positioning}

The emerging social representations broadly mirror the two principal positions on fracking, which are echoed in scientific discourse (Engelder, 2011; Howarth \& Ingraffea, 2011). On the one hand, fracking is represented as posing potential risks to human beings and the environment. In the corpora, this complex threat representation draws extensively upon three sources: (i) the 2010 film Gasland, (ii) the Lancashire seismic activity, and (iii) the debate on carbon reduction and climate change. On the other hand, fracking is represented as having benefits for employment, the economy, national security and the environment. Green energy is constructed as having environmental advantages over fracking but also as posing a threat to fracking and the economy. Thus, threat is deployed as a mobilizing factor on both sides of the debate - by pro-fracking and anti-fracking newspaper outlets alike. The threat representation remains important throughout the three corpora, although the sources of "evidence" that are invoked vary in accordance with the social context and ideological aim.

This article outlines the various notions that support the threat representation. In the first corpus, The Guardian and The Independent tend to construct fracking as a multi-faceted threat to human health and to the environment primarily by drawing upon the 2010 film Gasland, which, despite being a documentary film, is hyped up as a reliable source of information regarding fracking. Following reports of seismic activity in the Lancashire area, these outlets accentuate the scale and gravity of earthquakes and represent them as a typical consequence of fracking. While these notions accentuate the "threat" of fracking to human 
beings, these outlets also construct a threat to the environment by representing fracking as an impediment to carbon reduction. In the third corpus, there is a consolidation of the threat representation (Bauer, 2002) - Gasland, the seismic activity of Lancashire and carbon reduction are, collectively, presented in order to "evidence" the (constructed) threat of fracking. Crucially, in the third corpus, the threat representation (hitherto deployed in relation to fracking) is generalized to the UK government report itself. In this corpus, an evidencebased scientific report is denigrated and rejected in favour of Gasland, a documentary film. This attests to the tension between science and politics in the debate on environmental issues (Jaspal, Nerlich \& Koteyko, 2013).

Interestingly, the threat representation is also deployed in reporting in The Times and The Telegraph, albeit in relation to a different "target." These outlets appeal to the scarcity of energy sources and to the "threat of climate change." They represent fracking as a solution to this threat and therefore construct disengagement with fracking as irresponsible and threatening. Moreover, there is a construction of "green energy" (e.g. wind power) as a threat through the invocation of high costs associated with green energy, their negative implications for business and their negative impact for livelihoods. It is implied that, given that green energy will be expensive to implement, the most vulnerable members of society will suffer financially. This serves to deflect the threat representation from fracking onto green energy. In short, these outlets acknowledge that people are indeed threatened but the source of the threat is green energy, not fracking.

British broadsheet newspapers, collectively, create awareness of fracking as an important technological issue, but are divergent on the images of fracking that they disseminate. Yet, the two camps identified seem to converge on either positive or negative images (Wagner et al., 2002), and consolidation occurs as particular outlets use particular social representations to defend their respective positions on fracking (Bauer, 2002; Wagner, 2007). Wagner et al. (2002: 325) define "symbolic coping as the activity of a collectivity that attempts to maintain the integrity of its worldview by making sense of any new phenomenon". In our case, two ideologically distinct broadsheets that serve specific readership "collectivities," The Guardian and The Times respectively, report on fracking in ways that maintain the integrity of their readers' worldviews and help them make sense of the new phenomenon of fracking.

\section{Defending and contesting the practice fracking}

Newspaper outlets on either side of the divide attempt to reduce divergence and to safeguard their convergence upon either positive or negative images of fracking (Wagner et al., 2002). This article elucidates the important, strategic role of anchoring and objectification in this process (Moscovici, 1988). Initially, pro-fracking outlets anchor fracking to "green energy" since this serves the function of constructing fracking as a "clean" and viable energy source. Yet, later in the same corpus, green energy is denigrated as wasteful, irrational and counterproductive. In some articles, green policy is objectified metaphorically in terms of a "green mantra," which constructs the policy negatively as a religious ideology. The shift in representational patterns in The Telegraph and The Times can be attributed to the emerging social representation of fracking as a threat to green energy in The Guardian and The Independent. In short, green energy and fracking are constructed as being oppositional, conflicting sources of energy.

Over time, there is clearly a need to acknowledge the coercive and uniform social representation that fracking can cause seismic activity. However, pro-fracking outlets such as The Telegraph and The Times attenuate the scale and gravity of the seismic activity and "normalize" it by constructing it as "common" even in the absence of fracking. This shows that normalisation, the fourth stage of symbolic coping, can acknowledge a potential threat while downplaying the "menacing images" habitually used to convey it (Wagner et al., 2002). 
Conversely, in The Guardian and The Independent, the Lancashire "earthquakes" are represented as a typical outcome of fracking, which is to be expected if fracking is systematically implemented. There is an attempt to counteract the normalisation of fracking by introducing further divergence.

All outlets make strategic use of international comparisons in order to defend their respective positions on fracking. In anti-fracking outlets, the contexts of France, Quebec, Switzerland and the UK are homogenized in order to argue that a ban on fracking is warranted in the UK. This suggests that fracking would expose the UK population to this threat. Moreover, these outlets anchor the seismic activity in Lancashire to the "Oklahoma earthquakes" - this serves to extend the negative "consequences" of fracking in the US to the UK context. Yet, the international comparison is deemed by these outlets to be unfeasible when discussing the potential benefits of fracking - the UK and US contexts are constructed as being distinct and incomparable. It is suggested that the potential benefits of fracking in the US cannot possibly be applicable to the UK, given the differences in size and demographic distribution (Pool, 2011). Thus, in media reporting on fracking, international comparisons seem to reproduce particular images and representations of fracking in order to defend their respective positions.

\section{Conclusion}

In this article, we show the important role of the threat representation in polarizing the newspaper debate on fracking and describe the dynamics of this and other social representations over time. Moreover, we highlight the active and reciprocal engagement (i.e. contestation) of newspaper outlets with each others' respective social representations - there is a tendency to defend one's own position on fracking and to undermine competing positions. While this paper provides insight into the content and dynamics of social representations concerning fracking in the British broadsheet press, it would be useful to examine, in future research, how people cope symbolically with the advent of fracking through the lens of the theory of Collective Symbolic Coping (Wagner et al., 2002). At the moment, fracking in the UK is not yet a concrete social reality. Our analysis of UK press coverage lays out the landscape against which any symbolic coping with fracking will play out once it becomes a reality.

\section{REFERENCES}

Bauer, M.W. (1995). Familiarizing the unfamiliar. Public Understanding of Science, 4(2), 205-210.

Bauer, M.W. (2002) Controversial medical and agri-food biotechnology: a cultivation analysis. Public Understanding of Science, 11(2), 93-111.

Braun, V. \& Clark, V. (2006). Using thematic analysis in psychology. Qualitative Research in Psychology, 3, 77-101.

Carvalho, A. (2007). Ideological cultures and media discourses on scientific knowledge: Rereading news on climate change. Public Understanding of Science, 16, 223-24

Cuadrilla Resources (2011). Geomechanical study of Bowland shale seismicity: Executive summary. Cuadrilla Resources. Available at http://www.cuadrillaresources.com/wpcontent/uploads/2012/02/Executive-Summary-Geomechanical-Study-02-11-11.pdf 
Engelder, T. (2011). Should fracking stop? No, it's too valuable. Nature, 477, 271-75.

Farr, R. (1993). Common sense, science and social representations. Public Understanding of Science, 2(3), 189-204.

Forbis Jr., R. \& Kear, A. (2011). Fracking across the USA: Disparate political responses to unconventional energy development. Western Political Science Association 2011 Annual Meeting Paper.

Forsyth, P.J. \& Kay, J.A. (1980). The economic implications of North Sea oil revenues. Fiscal Studies, 1(3), 1-28.

Fox, J. (2010). Gasland. New Video Group.

Green, C., Styles, P. \& Baptie, B.J. (2012). Preese Hall Shale Gas Fracturing: Review and Recommendations for Induced Seismic Mitigation. Department for Energy and Climate Change, UK. Available at http://www.decc.gov.uk/assets/decc/11/meeting-energydemand/oil-gas/5055-preese-hall-shale-gas-fracturing-review-and-recomm.pdf

Howarth, R.W. \& Ingraffea, A. (2011). Should fracking stop? Yes, it's too high risk. Nature, $477,271-75$.

Jaspal, R. \& Nerlich, B. (in press). When climate science became climate politics: British media representations of climate change in 1988. Public Understanding of Science. doi:10.1177/0963662512440219

Jaspal, R., Nerlich, B. \& Koteyko, N. (2013). Contesting Science by Appealing to its Norms: Readers Discuss Climate Science in The Daily Mail. Science Communication, 35(3), 383410. doi:10.1177/1075547012459274

Jaspal, R., Turner, A. \& Nerlich, B. (in press). From Gasland to Gas Workers: Examining the Social and Psychological Impact of Fracking in YouTube Videos. Environmental Values.

Joffe, H. (2003). Risk: From perception to social representation. British Journal of Social Psychology, 42, 55-73.

Joffe, H. \& Haarhoff, G. (2002). Representations of far-flung illnesses: The case of Ebola in Britain. Social Science \& Medicine, 54, 955-969.

Moscovici, S. (1963). Attitudes and opinions. Annual Review of Psychology, 14, 231-260.

Moscovici, S. (1988). Notes towards a description of social representations. European Journal of Social Psychology, 18, 211-250.

Negro, E.E. (2012). Fracking wars: Federal, state and local conflicts over the regulation of natural gas activities. Zoning and Planning Law Report, 35(2), 1-16.

Nerlich, B. \& Jaspal, R. (2012). Metaphors we die by? Geoengineering, metaphors and the argument from catastrophe. Metaphor and Symbol, 27(2), 131-47. 
Nerlich, B. \& Jaspal, R. (2013). UK media representations of carbon capture and storage: Actors, frames and metaphors. Metaphor and the Social World, 3(1), 35-53.

O’Hara, S., Humphrey, M., Jaspal, R., Nerlich, B., Poberezshkaya (2012). Shale gas extraction in the UK: What the people think. Working paper, University of Nottingham. Available at http://www.scribd.com/doc/98974352/Public-Perceptions-of-Shale-Gas-in-theUK-7

Pool, R. (2011). Energy crisis postponed? [Power Shale Gas]. Engineering and Technology, 6(5), 88-90.

Rahm (2011). Regulating hydraulic fracturing in shale gas plays: The case of Texas. Energy Policy, 39(5), 2974-2981.

Rose, D., Efraim, D., Gervais, M-C., Joffe, H., Jovchelovitch, S. \& Morant, N. (1995) Questioning consensus in social representations theory. Papers on Social Representations 4(2): 1-6.SELP:

Stephenson, M. (2012). Frack responsibly and risks - and quakes - are small. New Scientist, 2849.

Van Sant, G. (2012). Promised Land. Participant media.

Wagner, W. (2007). Vernacular science knowledge: its role in everyday life communication. Public Understanding of Science, 16(1), 7-22.

Wagner, W., Kronberger, N. \& Seifert, F. (2002). Collective symbolic coping with new technology: Knowledge, images and public discourse. British Journal of Social Psychology, 41, 323-43.

\footnotetext{
${ }^{1} \mathrm{http}: / /$ www.chevron.com/globalissues/energypolicy/

$2 \mathrm{http}: / /$ www.guardian.co.uk/environment/2012/apr/17/gas-fracking-gets-green-light

38 April 2011, The Guardian

411 April 2011, The Daily Telegraph

511 April 2011, The Daily Telegraph

${ }^{6} 12$ April 2011, Daily Telegraph

73 April 2011, The Times

88 April 2011, The Times

911 April 2011, The Daily Telegraph

1013 April 2011, The Independent

1121 April 2011, The Guardian

1221 April 2011, The Guardian

1322 April 2011, The Guardian

1414 May 2011, The Independent

159 May 2011, The Guardian

${ }^{16} 1$ June 2011, The Independent

${ }^{17}$ May 14, Independent

1816 May 2011, The Independent

${ }^{19}$ May 19, The Independent

2016 May 2011, The Independent

${ }^{21} 17$ April 2011, The Sunday Times
} 
2218 November 2011, The Independent

233 November 2011, The Independent

244 November, Morning Star

258 November 2011, The Independent

${ }^{26} 3$ November 2011, The Guardian

${ }^{27}$ November 2 2011, The Guardian

287 November 2011, The Daily Telegraph

${ }^{29} 10$ November 2011, The Daily Telegraph

${ }^{30} 1$ April 2012, The Sunday Times

313 April 2012, The Daily Telegraph

3216 April 2012, The Telegraph

${ }_{33} 15$ April 2012, The Sunday Times

${ }^{34} 17$ April 2012, The Telegraph

3517 April 2012, The Guardian

${ }^{36} 17$ April 2012, The Guardian

3717 April 2012, The Guardian 